\title{
Humor styles and the ten personality dimensions from the Supernumerary Personality Inventory
}

\author{
Marisa L. Kfrerer ${ }^{E}$, Fulie Aitken Schermer (ID) A,B,C,D \\ University of Western Ontario, London, Canada
}

BACKGROUND

The present study examines the relationship between humor styles and the 10 Supernumerary Personality Inventory (SPI) traits to understand how humor styles correlate with personality dimensions "beyond the Big Five" model. Humor styles and the personality dimensions of the SPI have yet to be explored. Therefore, the aim of this study is to explore how humor styles correlate with traits outside of conventional personality models, in order to better understand humor expression related to personality traits.

PARTICIPANTS AND PROCEDURE

The data were from 693 adult participants (135 men and 560 women) from North America.

\section{RESULTS}

All four humor styles positively correlated with the SPI humorousness scale. The two positive humor styles, affiliative and self-enhancing, had significant positive correlations with the egotism SPI scale. The two negative humor styles, aggressive and self-defeating, had significant positive correlations with the SPI scales of seductiveness and manipulativeness and significant negative correlations with the integrity scale from the SPI. A sub-group of the sample $(n=471)$ also completed a Big Five personality measure. For this sample, the variance due to the Big Five was regressed out of the SPI scales.

\section{CONCLUSIONS}

The correlations between the SPI residuals and the humor style scores decreased from the unaltered SPI scale scores except for the aggressive humor style correlations, which were less affected, suggesting that this dimension of humor may have some variance "beyond" the Big Five.

KEY WORDS

humor styles; personality; adult human

CORRESPONDING AUTHOR - Prof. Julie A. Schermer, Management and Organizational Studies, University of Western

Ontario, 1151 Richmond Str., Social Science Centre, N6A 5C2 London, Canada, e-mail: jharris@uwo.ca

Authors' CONtribution - A: Study design · B: Data collection · C: Statistical analysis · D: Data interpretation ·

E: Manuscript preparation · F: Literature search · G: Funds collection

TO CITE THIS ARTICLE - Kfrerer, M. L., \& Schermer, J. A. (2020). Humor styles and the ten personality dimensions

from the Supernumerary Personality Inventory. Current Issues in Personality Psychology, 8(4), 352-360.

RECEIVED 12.07.2020 • REVIEWED 10.09.2020 • ACCEPTED 28.10.2020 • PUBLISHED 27.11.2020 


\section{BACKGROUND}

Humor can be thought of as an evolutionarily derived aspect of our human experience. Several decades ago, researchers began to investigate humor and its relationship to personality, establishing its space in the study of personality and commencing the development of many humor measures (Hehl \& Ruch, 1985). As Hehl and Ruch (1985) noted, which is still relevant today, "the exact number of dimensions of personality is still going on and therefore we cannot rely on a single model [therefore], it is very possible that humor variables will not lie perfectly into one axis in the personality space, but rather fall between two or more dimensions" (p. 707). Many decades later, in order to determine a conceptual framework for humor, Martin, Puhlik-Doris, Larsen, Gray, and Weir (2003) developed the Humor Styles Questionnaire (HSQ), using a 2X2 model, based on the knowledge that humor can function in both adaptive and maladaptive ways. Humor is seen as a tool used in ways that express one's self, and it can be used interpersonally (other-focused) or intra-personally (selffocused). In this view, humor itself is not inextricably linked to a specific personality type, but rather, it is linked to all people in ways that are indicative of human personality (Martin et al., 2003). As reviewed below, a range of literature has shown how the four humor styles correlate with the Big Five model of personality (openness to experience, conscientiousness, extraversion, agreeableness, and neuroticism), but what is less known is how humor styles correlate with personality dimensions designed to not fall within the Big Five model.

In order to understand the relationships between humor styles and personality, it is best to understand the constructs of both positive and negative humor. According to Martin et al. (2003), humor can be used in ways that focus on either the self or the other. For example, positive humor styles include both affiliative humor (practical joking and teasing, which is helpful in forming relationships with others), and self-enhancing humor (which is intrapersonal and used to cope with stress or adversity in life; Martin et al., 2003). The affiliative humor style is interpersonal and allows for healthy formation of relationships with others that is non-threatening. On the other hand, the self-enhancing humor style is much more intrapersonal, and indicative of one's own humorous outlook on life. Much literature has shown the relationship between these positive humor styles and the Big Five personality traits. For example, in a recent meta-analysis of 24 studies, Plessen et al. (2020) reported positive correlations of the affiliative humor style with both extraversion and openness to experience. Also from the metaanalysis, the self-enhancing humor style negatively correlated with neuroticism and positively with extraversion, agreeableness, and openness (Plessen et al., 2020).

In contrast, negative humor styles (aggressive and self-defeating) have been positively associated with the personality dimensions of neuroticism and extraversion (for aggressive humor style only), while negatively correlated with agreeableness and conscientiousness (Plessen et al., 2020). Aggressive humor is interpersonal behavior, such as teasing and ridicule, which is likely to hurt or alienate others. Self-defeating humor is defined in terms of neediness and low self-esteem, in which one puts one's own self down in one's humor (Martin et al., 2003). These negative types of humor correlate with personality traits such as neuroticism, as well as a tendency toward negative affect, anxiety, depression, and depressed affect (Kfrerer, Martin, \& Schermer, 2019).

The Humor Styles Questionnaire (HSQ) is a popular measure used in identifying individual differences in humor since its development (Martin, 2015). Debate on whether or not the HSQ's nonhumorous components dominate the humor-specific content is important to address (Ruch \& Heintz, 2013). In addressing the validity of the HSQ, Heintz (2019) found the construct validity for the four subscales to be sufficient. However, the self-defeating construct demonstrated insufficient convergent validity, suggesting the need for further investigation. Similarly, Ruch and Heintz (2017) stated that the self-defeating humor scale lacked sufficient construct validity when conducting an experimental manipulation on the HSQ's 32 items. However, the construct validity of the HSQ affiliative scale was supported with mixed results for the self-enhancing and aggressive scales (Ruch \& Heintz, 2017). Although these concerns have been raised, the HSQ is a widely used measure and uniquely encompasses both negative and positive uses for humor. Due to the lack of alternative measures, and the aim to address the negative and positive aspects of humor in the present research, the HSQ is thought to be a sufficient measure.

Although the relationship between humor styles and the Big Five personality traits is well known (for example, the meta-analysis by Plessen et al., 2020), less is known about the relationship between humor styles and non-Big Five dimensions. Some research has begun to look at the relationships between humor styles and traits beyond the Big Five (Schermer, Martin, Martin, Lynskey, \& Vernon, 2013; Veselka, Schermer, \& Vernon, 2011). A possible measure for these investigations into other personality dimensions is the Supernumerary Personality Inventory (SPI; Paunonen, 2002), which, as described below, was designed to assess personality traits that are both important in exploring human behavior and are not captured by traditional models of personality such as the Big Five. 


\section{THE SUPERNUMERARY PERSONALITY INVENTORY}

Lee, Ogunfowora, and Ashton (2005) demonstrated that the SPI scales are indeed outside of both the Big Five model, as well as the HEXACO model of personality. Specifically, Lee et al. (2005) found that only four of the 10 SPI dimensions (manipulativeness, integrity, egotism, and seductiveness) correlated significantly with the HEXACO dimension of Honesty-Humility. Furthermore, Veselka et al. (2011) found that the Dark Triad (Paulhus \& Williams, 2002) of personality (including the sub-clinical traits of Machiavellianism, psychopathy, and narcissism) were positively correlated with the SPI traits of seductiveness, manipulativeness, humorousness, risk-taking, and egotism. The Dark Triad of personality was also negatively correlated with the SPI dimensions of thriftiness, integrity, and femininity. These findings suggest that the SPI's constructs may be outside of contemporary models of personality and suggest its applicability to the humor styles constructs which themselves have also been found to correlate with the dark personality traits. For example, Veselka, Schermer, Martin, and Vernon (2010) found that those who scored higher on psychopathy and Machiavellianism also tended to use negative styles of humor. In contrast, individuals who scored higher on narcissism tended to use positive styles of humor. Zeigler-Hill and Besser (2011) examined the correlations between the separate dimensions of narcissism, grandiose and vulnerable, and humor styles. Positive correlations were reported between the four humor styles with grandiose narcissism but only the negative humor styles had significant positive correlations with vulnerable narcissism. However, it is important to note that these traits also positively correlate with narcissism, a personality dimension shown to relate to both positive and negative humor style use (Veselka et al., 2010; Zeigler-Hill \& Besser, 2011).

While this literature has added to our understanding of humor, less is known about how the four humor styles correlate with other personality dimensions "beyond" these traits (Paunonen \& Jackson, 2000). The SPI traits include conventionality, seductiveness, manipulation, thriftiness, humorousness, integrity, femininity, religiosity, risktaking, and egotism. Research studying personality beyond conventional models has been useful in understanding a greater breadth of individual differences. As stated by Paunonen (2002), the SPI scales were chosen in an attempt to capture traits that do not fit well within contemporary personality theories and models. Originally based on Paunonen and Jackson's (2000) critical review of the personality literature, the SPI's 10 dimensions encompass traits that are often excluded from conventional models of personality and human behavior. The SPI scales were not created as an alternative to the Big Five or other personality models, but rather were designed to tap into personality dimensions that are not captured by previous models. These 10 dimensions are thought to be distinct classes of behavior, although they may share common variance, specifically within the three overarching factors of Machiavellianism, Traditionalism, and Masculine-Feminine (Paunonen, 2002).

\section{THE PRESENT STUDY}

In the present study, the relationships between personality and humor styles are investigated by expanding upon the personality dimensions "beyond the Big Five" (Paunonen \& Jackson, 2000). Specifically, we examine the correlations between the 10 scales from Paunonen's (2002) SPI and the four humor styles from Martin et al.'s (2003) model. The purpose of the present study is to explore the correlations between the four humor styles from the HSQ and the 10 SPI personality traits in order to better understand how humor is expressed in relation to personality (SPI; Paunonen, 2002). As stated above, the SPI traits include conventionality, seductiveness, manipulation, thriftiness, humorousness, integrity, femininity, religiosity, risk-taking, and egotism. It is hypothesized that negative humor styles such as aggressive and self-defeating styles would correlate more with the SPI dimensions, due to the negative nature of these dimensions. More specifically, it may be hypothesized that the SPI personality traits related highly to Machiavellianism and psychopathy (including seductiveness, manipulativeness, humorousness, risk-taking, and egotism) may have significant correlations with the negative humor styles.

In addition to the correlations between the SPI and HSQ scales, a sub-sample of the participants also completed a standard Big Five personality measure. To further examine the possible unique variance in common between the SPI and HSQ scales, the variance due to the Big Five scales was regressed out of the SPI scales and the residual SPI scales were correlated with the HSQ scales. If the SPI scales are indeed "beyond the Big Five", the magnitude of the SPI and HSQ correlations should not decrease substantially.

\section{PARTICIPANTS AND PROCEDURE}

\section{PARTICIPANTS}

Participants were 693 adult volunteers (135 men and 560 women) from community environments within 
North America. As some of the participants were twins, this study only included one randomly selected individual from the pair with individual adult volunteers. The participants had a mean age of 40.29 years $(S D=16.72)$. Individuals were English speakers and were recruited through posters and word-of-mouth or snowballing. Of this sample, a sub-group of 471 individuals had also completed a Big Five personality measure two years previously. The average age of this sub-sample was 40.16 years $(S D=16.34)$ and it consisted of 72 men and 399 women.

\section{MEASURES}

Humor Styles Questionnaire (HSQ). Participants completed the HSQ (Martin et al., 2003), consisting of 32 items, eight for each of the four humor styles, including affiliative (sample item, "I enjoy making people laugh"), self-enhancing (sample item, "Even when I'm by myself, I'm often amused by the absurdities of life"), aggressive (sample item, "If someone makes a mistake, I will often tease them about it"), and selfdefeating (sample item, "Letting others laugh at me is my way of keeping my friends and family in good spirits"). Items are responded to using a 7-point Likert scale response format ranging from 1 (definitely disagree) to 7 (definitely agree). The internal consistency (coefficient $\alpha$ ) values for the scales ranged from .76 for the aggressive humor style scale to .82 for the affiliative humor style scale.

Supernumerary Personality Inventory (SPI). Also completed was the SPI (Paunonen, 2002), which includes 150 items. As stated by Paunonen (2002), items can be responded to using a true/false manner or a Likert scale. In the present study, a 1 (disagree) to 5 (agree) response key was used. The SPI measures 10 scales (each consisting of 15 items) and includes conventionality (example item, "I find it hard to change my personal habits"), seductiveness (example item, "I wear sexy clothes to attract the attention of others"), manipulativeness (example item, "I help others knowing that I may also need their help some day"), thriftiness (example item, "I use a budget to monitor my spending"), humorousness (example item, "In school, I was described as the class clown"), integrity (example item, "When traveling, I always declare everything at customs"), femininity (example item, "Violence disturbs me greatly"), religiosity (example item, "My spiritual beliefs help me through stressful times"), risk taking (example item, "People say I drive too fast"), egotism (example item, "I think that I am an attractive person"). Reliability (coefficient $\alpha$ ) values ranged from .67 for conventionality to .95 for religiosity.

Revised NEO Personality Inventory (NEO-PI-R). As stated above, a sub-sample of the participants had previously completed the NEO-PI-R (Costa \& Mc-
Crae, 1992), consisting of 240 items measuring the Big Five personality dimensions (openness, conscientiousness, extraversion, agreeableness, and neuroticism). For this sub-sample, the scale properties were sound (see Kowalski, Vernon, \& Schermer, 2019), as would be expected for a standardized personality assessment measure.

\section{PROCEDURE}

Participants completed an informed consent document, demographic items, the HSQ and SPI scales as part of a larger battery of measures. The sub-sample of participants had also completed the NEO-PI-R as part of a larger battery of scales at a previous data collection time. The study received institutional ethical approval.

\section{RESULTS}

Table 1 presents the correlations between the SPI and HSQ scales. All of the four humor style scores had significant positive correlations with the SPI humorousness scale. Of the other nine SPI scales, affiliative humor style scores had significant positive correlations with seductiveness, manipulativeness, risk-taking, and egotism. Significant negative correlations with conventionality, thriftiness, and integrity were found. For the self-enhancing humor style, there was a significant positive correlation with the SPI egotism scale. Significant positive correlations were found between the aggressive humor style and the SPI scales seductiveness, manipulativeness, risk taking, and egotism. Significant negative correlations were found with thriftiness, integrity, femininity, and religiosity. For the self-defeating humor style scores, there were significant positive correlations with seductiveness and manipulativeness and self-defeating humor style scores had a significant negative correlation with integrity.

As the SPI has been described as measuring personality dimensions "beyond the Big Five", for the sub-sample of participants who also completed the NEO-PI-R, the correlations between the Big Five scales and the SPI were calculated. As listed in Table 2, neuroticism had low to moderate correlations with the SPI with significant positive correlations with seductiveness, manipulativeness, and femininity, and a significant negative correlation with integrity. Extraversion had more significant correlations with the SPI with significant positive correlations with seductiveness, manipulativeness, humorousness, risk-taking, and egotism and a significant negative correlation with thriftiness. Openness had significant positive correlations with the SPI scales seductiveness, humorousness, risk-taking, and ego- 


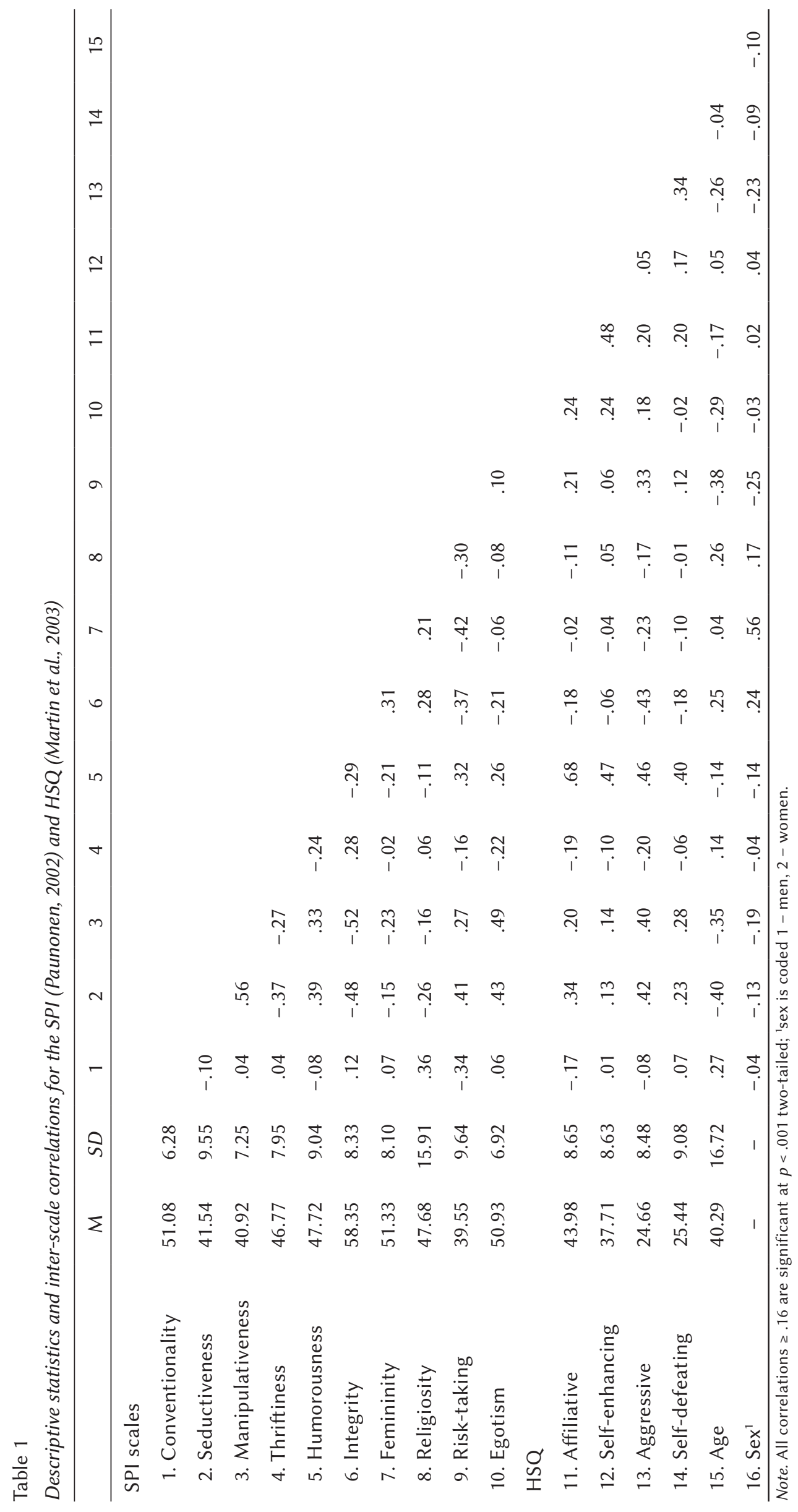


Table 2

Correlations between the NEO-PI-R (Costa \& McRae, 1992) Big Five scales and the SPI (Paunonen, 2002) scales

\begin{tabular}{lccccc}
\hline SPI scales & Neuroticism & Extraversion & Openness & Agreeableness & Conscientiousness \\
\hline 1. Conventionality & .08 & -.10 & -.39 & .06 & .05 \\
2. Seductiveness & .23 & .28 & .32 & -.42 & -.25 \\
3. Manipulativeness & .20 & .26 & .12 & -.53 & -.18 \\
4. Thriftiness & -.15 & -.24 & -.17 & .19 & .32 \\
5. Humorousness & -.07 & .36 & .34 & -.17 & -.20 \\
6. Integrity & -.20 & -.04 & -.04 & .49 & .46 \\
7. Femininity & .21 & .03 & .07 & .25 & .09 \\
8. Religiosity & -.06 & -.10 & -.25 & .26 & .10 \\
9. Risk-taking & .01 & .24 & .33 & -.25 & -.30 \\
10. Egotism & -.13 & .46 & .32 & -.31 & .22 \\
\hline Note. All correlations $\geq .18$ are significant at $p<.001$ two-tailed. & & &
\end{tabular}

Table 3

Correlations between the SPI (Paunonen, 2002) scale residuals (with variance due to the Big Five scales) and the HSQ (Martin et al., 2003)

\begin{tabular}{lcccc}
\hline SPI scales & Affiliative & Self-Enhancing & Aggressive & Self-Defeating \\
\hline 1. Conventionality & -.01 & .10 & .01 & .15 \\
2. Seductiveness & .12 & .03 & .18 & .15 \\
3. Manipulativeness & .05 & .13 & .14 & .28 \\
4. Thriftiness & .01 & -.06 & -.06 & .02 \\
5. Humorousness & .48 & .33 & .36 & .39 \\
6. Integrity & -.05 & -.09 & -.16 & -.14 \\
7. Femininity & .03 & -.02 & -.12 & -.11 \\
8. Religiosity & .07 & .11 & -.04 & .06 \\
9. Risk-taking & .04 & -.04 & .08 & .01 \\
10. Egotism & -.01 & .02 & -.02 & -.04 \\
\hline
\end{tabular}

Note. All correlations $\geq .18$ are significant at $p<.001$ two-tailed.

tism, and significant negative correlations with the SPI scales conventionality, thriftiness, and religiosity. Agreeableness had significant positive correlations with the SPI scales thriftiness, integrity, femininity, religiosity, and significant negative correlations with the SPI scales seductiveness, manipulativeness, humorousness, risk-taking, and egotism. Conscientiousness had significant positive correlations with the SPI scales thriftiness, integrity, and egotism, and significant negative correlations with the SPI scales seductiveness, manipulativeness, humorousness, and risk-taking.

To assess whether there was variance in common between the SPI scales and the humor style scales without the influence of the Big Five personality dimensions, for each SPI scale, the variance due to the Big Five was statistically regressed out of the SPI scale variance and the residual SPI scale scores were then correlated with the HSQ scales. The resulting correlations are reported in Table 3. When comparing the values in Table 3 to those reported in Table 1, the correlations between the SPI residuals and the HSQ drop in magnitude, reflecting the variance in common between the SPI and the Big Five. What remains significant is the positive correlation between seductiveness and the aggressive humor style and between manipulativeness and the self-defeating humor style. Each of the four humor style scores correlated significantly and positively with the SPI residual humorousness scale. 


\section{DISCUSSION}

The present study explored the relationships between humor styles from the HSQ (Martin et al., 2003) and the 10 personality dimensions of the SPI (Paunonen, 2002). All four humor style scales had significant positive correlations with the SPI humorousness scale, suggesting some degree of convergent validity. Affiliative humor style, as described above, involves using humor in a positive manner to improve group cohesiveness (Martin et al., 2003) and has been found to correlate with extraversion, openness to experience (Plessen et al., 2020), and narcissism (Veselka et al., 2010; Zeigler-Hill \& Besser, 2011). Of the nine other SPI scales, affiliative humor style scores had significant positive correlations with seductiveness, manipulativeness, risk-taking, and egotism and significant negative correlations with conventionality, thriftiness, and integrity. As affiliative humor style has been found to positively correlate with narcissism, this association may explain the positive correlations between seductive and egotistical scale scores and the affiliative humor style. How affiliative humor style is associated with other personality dimensions "beyond the Big Five", such as the Dark Tetrad's dimension of sadism, requires future research.

Self-enhancing humor style reflects using humor to improve one's mood (Martin et al., 2003) and is associated with more positive mental health and reduced loneliness (Schermer et al., 2017). The positive association between the self-enhancing humor style and egotism found in the present study may reflect the findings reported by Zeigler-Hill and Besser (2011), who reported a significant correlation between the self-enhancing humor style and grandiose narcissism. Further research may want to examine how the self-enhancing humor style is related to both narcissism and egotism from self-report and possibly with peer reports to explain the associations found.

An aggressive humor style is characteristic of an individual using humor to belittle others (Martin et al., 2003), and the significant negative correlations reported in Table 1 with integrity, femininity, and religiosity may reflect this callous disregard for others, although the significant negative correlation with thriftiness fails to fall within the aggressivebullying cluster. Paunonen (2002, p. 7) defines thriftiness as the "safeguarding of personal resources (for example, money, time or effort)" and which may, in turn, be related to aggressive use of safeguarding in this respect when resources are threatened. Future research is needed to further understand this relationship. Aggressive humor style scores also had positive correlations with seductiveness, manipulativeness, risk taking, and egotism. These associations with the aggressive humor style and manipulativeness, seductiveness, and low integrity may reflect the association between the aggressive humor style and Machiavellianism (Veselka et al., 2010).

The self-defeating humor style involves using the self as the target of humor (Martin et al., 2003) and is associated with self-report loneliness (Schermer et al., 2017) and borderline personality disorder features such as affect instability, identity disturbance, negative relationships, and self-harm (Schermer et al., 2015). Veselka et al. (2010) reported that the self-defeating humor style had positive correlations with psychopathy and Machiavellianism and a nonsignificant correlation with narcissism from the Dark Triad. The Machiavellianism correlation may explain the significant positive correlations with seductiveness and manipulativeness as well as the negative correlation with integrity, although these results should be replicated in future research with a more diverse sample.

As noted, in order to solidify the relationship between the SPI and HSQ beyond the Big Five model, the variance from the Big Five was regressed out of each SPI scale. The SPI residual scores were correlated with the HSQ, resulting in a decreased magnitude for almost all of the correlations (as shown in Table 3). This may, in turn, demonstrate the SPI's correlation with the Big Five, which warrants further investigation. All four subscales of Humor Styles continued to correlate positively with the SPI dimension of Humorousness, showing further validation for this dimension outside of the Big Five. Furthermore, the SPI scale of Conventionality was not affected, possibly due to its focus on culture and traditional value/ belief systems, which may have less in common with the Big Five personality dimensions. Two statistically significant relationships remained and are of further interest. First, seductiveness significantly and positively correlated with the aggressive humor style. This may be due to the nature of the seductiveness trait, namely to attract the opposite sex by way of manipulation or control (Paunonen, 2002). Paunonen (2002) also notes that a highly seductive person is charming, flirtatious and may seek an aspect of control when attracting the opposite sex. Martin et al. (2003) stated that the aggressive humor style resulted in the alienation of others. Possibly individuals may use aggressive humor and seduction in an attempt to attract partners; whether it is successful or not warrants future research.

Second, manipulativeness was positively correlated with the self-defeating humor style. Self-defeating humor involves putting one's own self down for the sake of the joke, but more importantly to amuse others, or to remain in denial of one's shortcomings (Martin et al., 2003). Manipulativeness is defined as one's ability or skill in influencing people in their actions, usually without awareness (Paunonen, 2002, p. 6). Self-defeating humor may therefore be used by manipulative individuals in order to be perceived on 
the surface as quite astute, diplomatic or amusing, while the underlying intentions may be to manipulate others' actions. Possibly future research may want to investigate how those scoring high in the self-defeating humor style negotiate with others.

\section{LIMITATIONS}

We acknowledge that the present study may have several limitations. In this study, participants completed questionnaires, making self-report a possible limitation. The present sample was also predominantly female, and of North American/English-speaking descent. Future studies may wish to replicate this study with diverse populations both to further replicate the relationships between humor styles and the SPI and to examine the properties of the HSQ in other languages, as Schermer et al. (2019) reported that the HSQ did not perform well in every one of the 28 countries they sampled. A further possible limitation was that those who completed the Big Five measure did so two years prior to completing the SPI. Possibly there might be an effect due to the time delay. Future studies should examine how the SPI correlates with other interpersonal variables without the variance due to the Big Five personality dimensions assessed at the same time.

\section{CONCLUSIONS}

The present study uncovered several interesting findings regarding humor styles and Paunonen's (2002) SPI traits, a scale which has not been extensively examined in past research. First, the SPI humorousness scale had strong positive correlations with all four of the humor styles, remaining after removing the variance in common with the Big Five personality factors. The SPI egotism scale positively correlated with the positive humor styles and also with the aggressive humor style but not with the self-defeating humor style. When variance regarding the Big Five was removed, self-defeating humor significantly correlated with manipulativeness, while aggressive humor correlated with seductiveness. Future research in these areas is discussed. In general, the findings suggest that humor styles correlate with some of the personality traits that are "beyond the Big Five". How humor styles relate to other personality dimensions, such as the sadism component mentioned above, is an area requiring further research.

\section{ACKNOWLEDGEMENT}

Thank you to P. A. Vernon for access to the data for individual cases.

\section{RefERENCES}

Costa, P. T., Jr, \& McCrae, R. R. (1992). The revised NEO Personality Inventory (NEO PI-R) and NEO FiveFactor Inventory (NEO-FFI) professional manual. Odessa, FL: Psychological Assessment Resources.

Hehl, F., \& Ruch, W. (1985). The location of sense of humor within comprehensive personality spaces: an exploratory study. Personality and Individual Differences, 6, 703-715. https://doi.org/10.1016/01918869(85)90081-9

Heintz, S. (2019). Do others judge my humor style as I do? Self-other agreement and construct validity of the Humor Styles Questionnaire. European Journal of Psychological Assessment, 35, 625-632. https://doi.org/10.1027/1015-5759/a000440

Kfrerer, M. L., Martin, N. G., \& Schermer, J. A. (2019). A behavior genetic analysis of the relationship between humor styles and depression. Humor, 32, 417-431. https://doi.org/10.1515/humor-2017-0098

Kowalski, C. M., Vernon, P. A., \& Schermer, J. A. (2019). The Dark Triad and facets of personality. Current Psychology. https://doi.org/10.1007/s12144019-00518-0

Lee, K., Ogunfowora, B., \& Ashton, M. C. (2005). Personality traits beyond the Big Five: Are they within the HEXACO space? Journal of Personality, 73, 1437-1463. https://doi.org/10.1111/j.14676494.2005.00354.x

Martin, R., Puhlik-Doris, P., Larsen, G., Gray, J., \& Weir, K. (2003). Individual differences in uses of humor and their relation to psychological well-being: Development of the Humor Styles Questionnaire. Journal of Research in Personality, 37, 48-75. https://doi.org/10.1016/S0092-6566(02)00534-2

Martin, R. A. (2015). On the challenges of measuring humor styles: Response to Heintz and Ruch. Humor, 28, 635-639. https://doi.org/10.1515/humor-2015-0096

Paulhus, D. L., \& Williams, K. M. (2002). The Dark Triad of personality: Narcissism, Machiavellianism and psychopathy. Journal of Research in Personality, 36, 556-563. https://doi.org/10.1016/S00926566(02)00505-6

Paunonen, S. V. (2002). Design and construction of the Supernumerary Personality Inventory. The University of Western Ontario Psychology Research Bulletin, 763.

Paunonen, S. V., \& Jackson, D. N. (2000). What is beyond the Big Five? Plenty! Journal of Personality, 68, 821-835. https://doi.org/10.1111/14676494.00117

Plessen, C. Y., Franken, F. R., Ster, C., Schmid, R. R., Wolfmayr, C., Mayer, A., Sobisch, M., Kathofer, M., Rattner, K., Kotlyar, E., Maierwieser, R. J., \& Tran, U. S. (2020). Humor styles and personality: a systematic review and meta-analysis on the relations between humor styles and the Big Five 
personality traits. Personality and Individual Differences, 154, article 109676. https://doi.org/10.1016/j. paid.2019.109676

Ruch, W., \& Heintz, S. (2013). Humour styles, personality and psychological well-being: What's humour got to do with it? European Journal of Humour Research, 1, 1-24. https://doi.org/10.7592/ ejhr2013.1.4.ruch

Ruch, W., \& Heintz, S. (2017). Experimentally manipulating items informs on the (limited) construct and criterion validity of the Humor Styles Questionnaire. Frontiers in Psychology, 8, article 616. https://doi.org/10.3389/fpsyg.2017.00616

Schermer, J. A., Martin, R. A., Martin, N. G., Lynskey, M. T., Trull, T. J., \& Vernon, P. A. (2015). Humor styles and borderline personality. Personality and Individual Differences, 87, 158-161. https://doi. org/10.1016/j.paid.2015.07.043

Schermer, J. A., Martin, R. A., Martin, N. G., Lynskey, M., \& Vernon, P. A. (2013). The general factor of personality and humor styles. Personality and Individual Differences, 54, 890-893. https://doi. org/10.1016/j.paid.2012.12.026

Schermer, J. A., Martin, R. A., Vernon, P. A., Martin, N. G., Conde, L. C., Statham, D., \& Lynskey, M. T. (2017). Lonely people tend to make fun of themselves: a behavior genetic analysis of humor styles and loneliness. Personality and Individual Differences, 117, 71-73. https://doi.org/10.1016/j.paid.2017.05.042

Schermer, J. A., Rogoza, R., Kwiatkowska, M. M., Kowalski, C. M., Aquino, S., Ardi, R., ... Krammer, G. (2019). Humor styles across 28 countries. Current Psychology. https://doi.org/10.1007/s12144-019-00552-y

Veselka, L., Schermer, J. A., Martin, R. A., \& Vernon, P. A. (2010). Relations between humor styles and the Dark Triad traits of personality. Personality and Individual Differences, 48, 772-774. https:// doi.org/10.1016/j.paid.2010.01.017

Veselka, L., Schermer, J. A., \& Vernon, P. A. (2011). Beyond the Big Five: The Dark Triad and the Supernumerary Personality Inventory. Twin Research and Human Genetics, 14, 158-168. https://doi. org/10.1375/twin.14.2.158

Zeigler-Hill, V., \& Besser, A. (2011). Humor style mediates the association between pathological narcissism and self-esteem. Personality and Individual Differences, 50, 1196-1201. https://doi.org/10.1016/j. paid.2011.02.006 